\title{
Acute mercurial pneumonitis
}

\author{
JAMES MILNE, ALLEN CHRISTOPHERS, and PAMELA DE SILVA \\ The Industrial Hygiene Division, Department of Health, 19 Park Street, \\ South Yarra 3141, Victoria, Australia
}

\begin{abstract}
Milne, J., Christophers, A., and de Silva, Pamela (1970). Brit. J. industr. Med., 27, 334-338. Acute mercurial pneumonitis. Mercury vapour has been shown to cause acute effects on the lung when inhaled in high concentrations. Four men, exposed to mercury inside a tank, developed, hours later, signs and symptoms of an acute febrile illness with severe pulmonary irritation, characterized by fever, rigors, cough, dyspnoea, and tightness in the chest. A review of the literature revealed that this syndrome had been described and investigated previously in fewer than 20 cases during the past $\mathbf{4 0}$ years, and is apparently little known.

Fatalities have been described, particularly in children, and necropsy evidence has consistently revealed the pattern of an acute diffuse interstitial pneumonitis, accompanied by profuse fibrinous exudation and erosion of the bronchial and bronchiolar lining. The two common features in all reports are the heating of mercury or the entering into a confined space, or both. Adequate respiratory protection by an efficient air-supplied respirator is mandatory in industrial circumstances of the kind described in this report.
\end{abstract}

A rare feature of mercury poisoning is acute pulmonary irritation. The literature contains few examples. It is noteworthy that Ramazzini is quoted by Hunter (1957) as stating that asthma is a final result of heavy mercury exposure:

'Those who make mirrors become palsied and asthmatic from handling mercury.' Otherwise Hunter's extensive text makes no mention of acute mercurial effects on the lung, and this omission is common to most occupational health textbooks. Nevertheless, the evidence is clear (though sparse) that inhalation of mercury vapour in sufficient concentration over periods of a few hours may cause irritation and inflammation of the respiratory tract with resultant acute tracheo-bronchitis, bronchiolitis, pneumonitis and perhaps death.

Hopmann (1928) described two separate episodes of acute industrial mercury poisoning, on each occasion affecting two men inside a boiler who were exposed to mercury vapour for some hours. All four showed cough and signs of respiratory irritation, and the urinary mercury was high in all.

Christensen, Krogh, and Nielsen (1937), whilst studying the effects of inhaling carbon dioxide in a closed chamber where mercury had also been spilt, noted 'bronchial irritation, coughing and severe headache after a few hours', and 'in the night a few hours later the conditions became worse, with increased temperature, dyspnoea and nausea'. They further noted that 'experimental animals (guinea pigs, rats and mice) were killed by the air in the chamber in 24 to $\mathbf{4 8}$ hours with severe pulmonary oedema', and investigation showed that 'the symptoms were due to mercury poisoning from droplets spilled on the floor'.

Campbell (1948) described the death of a female child of four months exposed to mercury vapour when the father evaporated small quantities of mercury on two occasions in a kitchen, by dropping metallic mercury onto a red hot stove. 'Each lot of mercury vaporized within five minutes, and a greyish cloud dispersed into the atmosphere of the apartment.' Five hours later the child was considered to have mercurial pneumonitis and three days later she suddenly developed acute pulmonary oedema and died. Mother and father suffered 'fatigue, nausea and abdominal cramps'.

King (1954) reported a case of acute pneumonitis 
and exudative bronchitis in a 29-year-old man who heated a mercury gold amalgam over a kitchen stove. An hour or so later he developed a 'fit of coughing'; several hours later he complained of pain in the chest and was 'acutely ill, vomiting, febrile, slightly cyanotic and very dyspnoeic'. A portable chest radiograph on admission to hospital revealed 'bilateral bronchopulmonary abnormality probably indicative of aspiration and exudative type bronchitis'. He was given antibiotics, BAL and oxygen and was finally discharged after 15 days, said to be 'entirely well'.

Matthes, Kirschner, Yow, and Brennan (1958) described four cases of acute poisoning associated with inhalation of mercury vapour. The cause was nocturnal exposure of a mother and three children to mercury vapour, from a heated stove which had recently been painted with a mixture of mercury, turpentine and aluminium paint. All experienced 'respiratory difficulty' the following morning. Thirtysix hours later one child died after three hours of restlessness, dyspnoea and 'grunting respirations'.... 'The siblings were febrile, lethargic, anorexic, dyspnoeic and exhibited marked thirst'. Postmortem examination of the dead child revealed that 'the major pathologic changes were apparent in the lungs' which showed 'a marked exudation of fibrinrich fluid into alveoli and interstitial tissues'.... . 'There was almost total exclusion of air from the lungs'.

A second child aged 30 months died 36 hours later in hospital, and post-mortem examination revealed a similar picture but 'the bronchial and bronchiolar erosion and inflammation were more severe'.

The third child aged 4 months unfortunately developed bilateral pneumothoraces and despite most intensive treatment died on the fifth day after admission to hospital; post-mortem examination revealed bronchial erosion as in the second child. Exudation of fibrinous fluid was more marked than in either of the other siblings.

The mother had been admitted to hospital with 'fever, shortness of breath, lethargy and cough', and 'appeared acutely ill'. She remained so for $\mathbf{4 8}$ hours, then steadily improved and was discharged after four weeks in hospital.

It was noted by the authors that the common symptoms and signs in their series were lethargy, tachypnoea, restlessness, diarrhoea, cough and fever. They summarized the findings of Hopmann (1928), Campbell (1948), and King (1954), previously mentioned, together with their own to show that $60 \%$ of cases showed cough, central nervous system manifestations, tachypnoea, fever and gastrointestinal symptoms.

Their paper is of importance because of the correlation of clinical features with later post-mortem findings which indicated that 'the significant patho- logic findings in each case were in the lungs, where there was evidence of inhalation of a severe irritant with erosive bronchitis and bronchiolitis, and severe interstitial pneumonitis'.

Tennant, Johnston, and Wells (1961) reported the first death in an adult from acute interstitial pneumonitis associated with inhalation of mercury vapour. The man was one of a group of eight exposed 'without precautionary measures' for about five hours whilst attempting to recover a large quantity of mercury which had spilled from a ruptured mercury vapour boiler used for generating electricity. 'This mercury was warm but not hot enough to burn the skin.' The same night the men generally complained of shaking, chills, nausea, general malaise, chest tightness, and 'vague respiratory symptoms'. All but one gradually improved. This unfortunate man complained over the next $\mathbf{4 8}$ hours of severe difficulty in breathing, with episodes of paroxysmal coughing and pain in the chest. 'Because of the increasing severity of his respiratory difficulties he was treated with antibiotics and was thought to have a viral or bacterial pneumonitis. He became rapidly worse and expired at home- 72 hours after exposure, and was brought to hospital for post-mortem examination.'

Because of the close resemblance in that case to the post-mortem findings in the cases of Matthes and his colleagues (1958) it is worth while quoting some of the histological details noted in the lungs:

'Microscopic examination: Sections of the lungs showed a diffuse pneumonic process which was characterized by a marked interstitial oedema. The alveolar spaces contained oedema fluid with a minimal amount of cellular exudate, chiefly lymphocytes. Many of the alveolar spaces were linked by a fibrinous material which formed a pink hyaline membrane....'

No bacterial organism was cultured and viral studies failed to isolate a virus.

Analysis of tissue specimens showed:

liver $1.13 \mathrm{mg}$ mercury per $100 \mathrm{~g}$ tissue kidney $4.7 \mathrm{mg}$ mercury per $100 \mathrm{~g}$ tissue lung $0.36 \mathrm{mg}$ mercury per $100 \mathrm{~g}$ tissue

It should be noted that the kidneys and liver were normal, both macroscopically and microscopically.

The diagnosis was stated to be acute diffuse interstitial pneumonitis secondary to the inhalation of mercury vapour.

Four other men with symptoms that had not resolved were then admitted to hospital for examination. All were regarded as cases of mercurial pneumonitis on the basis of exposure and of a clinical picture in three cases of general malaise, dyspnoea, chest pain, fever and productive cough. The fourth case had a similar exposure, with no cough, chest pain or dyspnoea, but had developed general malaise, weakness and headache four hours after exposure and next day complained of 'marked pain in teeth and 
gums'. All four exhibited diffuse changes in the chest radiograph which slowly resolved.

Haddad and Stenberg (1963) reported two cases of the 'irritative effects of mercury vapour on the tracheo-bronchial tree' due to vaporization of mercury on a kitchen stove, in an effort by the man concerned to extract gold from sand samples. The first patient, a man aged 25 , was admitted to hospital about six hours after inhaling the mercury vapour and was said to be 'acutely ill' with fever, chills, nausea, vomiting and a severe non-productive cough and chest pain. He excreted $0.54 \mathrm{mg}$ mercury per litre of urine (and a total of $2.10 \mathrm{mg}$ ) in the first 24 hours. For the second 24 hours the figures were $0.35 \mathrm{mg} /$ litre and $1.8 \mathrm{mg}$ in 24 hours. Two weeks after the onset of the illness, at the time of his discharge from hospital, the patient still noted a metallic taste but urinary mercury had dropped to $0.14 \mathrm{mg} /$ litre and $0.16 \mathrm{mg}$ in 24 hours.

The second patient, the wife of the first, had been in an adjacent room. She developed substernal pain and a non-productive cough. Her temperature was raised and she also complained of urinary frequency and burning, together with an herpetic lesion on the upper lip. There were apparently no chest signs on examination. On the first day in hospital she excreted only $0.08 \mathrm{mg}$ of mercury per litre of urine, and within three days she was asymptomatic and was discharged. It seems doubtful, in retrospect, that she suffered from severe bronchitis due to mercury vapour, but she obviously had absorbed mercury and had suffered some bronchial irritation. Nevertheless those authors quite rightly, in the review, point out that the most frequent features reported are 'pharyngeal ulcerations and cough; less frequently fever, chest pain, abdominal pain, headache, dyspnoea, central nervous system symptoms, and vomiting', and that unlike other types of mercury poisoning 'the irritative effects on the tracheobronchial tree constitute the prime danger to life'.

\section{Case reports}

We have seen recently four cases of men exposed to a high concentration of mercury vapour in the respired air for a period of several hours in a confined space. The details are as follows:

A large steel cylindrical tank of approximately $600 \mathrm{~m}^{3}$ volume was used to store caustic soda produced in the course of extracting chlorine from a brine solution. There were three openings in the roof of the tank with diameters of approximately $50 \mathrm{~cm}, 15 \mathrm{~cm}$ and $10 \mathrm{~cm}$ respectively. Near the floor in the side was a manhole of about $60 \mathrm{~cm}$ diameter. Mercury is used as an electrode in the electrolysis of the brine, and over the years small mercurial globules had been carried over into the tank with the caustic soda and had settled to the floor. The tank had originally been thought to require no regular maintenance and was presumed to have an indefinite life, but repairs were eventually required. On an occasion when the caustic soda had been emptied and the tank flushed, a scaffolding was to be erected inside the tank with the idea of welding the steel near the upper end of the tank.

It was realized that the confined space was a potential hazard, so an air blower was attached to the $50-\mathrm{cm}$ diameter outlet in the roof, blowing air out at the rate of about $85 \mathrm{~m}^{3} /$ minute. The men were to gain entry to the tank through the manhole in the side wall near the floor. Mercury could be seen in globules on the floor after flushing out the caustic with water. Furthermore a small steam heating pipe, used normally to maintain the caustic in fluid form, had inadvertently been left turned on.

\section{Case 1}

The first man (W.C.H., aged 49) entered the tank on Monday at about 4.30 p.m. and remained inside for about 5 hours. He was supposed to have been wearing a plastic hood, supplied with air from an uncontaminated outside source, but there is some doubt about this. His job was to finish the flushing of caustic by hosing with water.

On leaving the tank he began to feel aches and pains in the back, arms and neck and he started to shiver. A cough developed which became more persistent. He went home and became worse, so he lay down in front of a gas fire where he remained throughout the night, sweating and coughing and shivering, with a tight feeling across the chest. The next day he was too ill to work, but the following day (Wednesday) he reported back to the foreman stating that he was ready for work, although still coughing and having a tight feeling across the chest.

\section{Case 2}

A second man (A.I., aged 39) had worked outside the tank on Monday morning hosing the tank from the outside manhole. He complained of pain in the neck and shoulders that night. The next day he worked inside the tank helping the scaffolders for about 4 hours. He sweated whilst doing this and that night suffered abdominal pains and a dry throat but did not cough.

The following day (Wednesday) he spent about an hour in the tank, and again noticed sweating and a dry throat that night. Over the next four days he felt tired, vomited once, and complained of slight tightness in the chest plus a sore tongue, but had felt well enough on the Thursday to have an immunizing injection against influenza.

Case 3

A third man (W.F., aged 46) had been a scaffolder for 21 years, with good general health. On the Tuesday afternoon he obtained permission to enter the tank and began erecting the scaffold. He noticed the particles of mercury all over the tank floor. He felt warm and took off his sweater but was otherwise conscious of no discomfort, and after $2 \frac{1}{2}$ hours he finished, left the tank and went home feeling well. On the way home he started to cough and shiver. The usual time to reach his home from the bus stop was 7 minutes, but that night he was shivering so violently that it took him half an hour. He felt very cold and on reaching home he sat on the electric heater, then had a hot bath, a drink of milk and went to bed. Mixed with the milk was a small amount of alcohol which he rarely drank. He slept fitfully and restlessly, still shivering and coughing, and was short of breath throughout the 
night. By morning his symptoms had abated, but he had a slight tremor and pains in the back of the head. His chest was 'sore inside' and the shortness of breath continued for two more days. He refused to enter the tank on the Wednesday because the others had also been sick and he felt that the job had caused this.

A chest radiograph taken a week later was said by his doctor to be clear.

\section{Case 4}

The fourth man (L.M.F., aged 48) started work erecting the scaffold at the same time as the previous man and was exposed for the same period to the same conditions inside the tank. He noticed the hot pipe near the floor and the globules of mercury scattered about. Half an hour after leaving the tank he had a coughing fit and his throat and chest felt 'red raw'. He then left for home by car and en route began to suffer with abdominal pains, headache and shivering.

Arriving home he went straight to bed. The coughing continued and though he began to sweat heavily he felt cold. Breathing became difficult, short and gasping and he had several episodes of delirium throughout the night. The next morning he awakened at 6 a.m. feeling 'wet and burning' but not shivering. He felt 'feverish' and could not eat his breakfast, but although he was gasping he went to work, where in compariy with others he dismantled the scaffold. When he took a deep breath he got a dragging pain in the chest, and his cough and headache persisted. He was short of breath on exertion and tired very readily. Over the next three days the symptoms slowly subsided but eight days after his exposure he noticed a 'slight catch in the chest' on taking a deep breath, and felt that he tired more quickly than usual. A week later these symptoms still persisted to a small extent together with an incomplete return of his usual appetite. About one month later ne complained of sleeplessness and nightmares in which he had visions of huge pipes sımilar to those seen in his attacks of delirium.

It is unfortunate that the incident did not come to our notice until a week had elapsed. Urinary mercury estimations, taken 10 to 14 days after exposure and then one month later, are shown (Table 1).

\section{TABLE 1}

\section{Urinary Mercury in the Four Patients}

\begin{tabular}{|c|c|c|c|c|}
\hline \multirow{2}{*}{ Patient } & \multicolumn{2}{|c|}{$\begin{array}{c}\text { 10-14 days after } \\
\text { exposure }\end{array}$} & \multicolumn{2}{|c|}{ One month later } \\
\hline & $m g \quad H g / l$ & $\begin{array}{c}24 \mathrm{hr} \\
\text { excretion } \\
(\mathrm{mg})\end{array}$ & $m g \quad H g / l$ & $\begin{array}{c}24 \mathrm{hr} \\
\text { excretion } \\
(\mathrm{mg})\end{array}$ \\
\hline $\begin{array}{ll}\text { W.C.H. } & \cdots \\
\text { A.I. } & \quad \\
\text { W.F. } & \quad \\
\text { L.M.F. } & \quad \text { }\end{array}$ & $\begin{array}{l}0 \cdot 13 \\
0 \cdot 10 \\
0 \cdot 10 \\
0 \cdot 10\end{array}$ & $\begin{array}{l}0 \cdot 12 \\
0 \cdot 10 \\
0 \cdot 17 \\
0 \cdot 10\end{array}$ & $\begin{array}{l}-\overline{0.06} \\
0.07 \\
0.02\end{array}$ & $\begin{array}{l}-\overline{0.05} \\
0 \cdot 11 \\
0.04\end{array}$ \\
\hline
\end{tabular}

These levels confirm an exposure to mercury and show the expected fall after some weeks free from mercury.

Unfortunately, by the time these men had been inter- vie'ved and examined, the tank had been repaired and was again in operation as a caustic storage. However, several weeks later, the opportunity arose to carry out estimations of mercury-in-air under somewhat similar conditions in a tank of approximately similar dimensions, with the same 'Airmover' in operation. The results of this simulation are shown (Table 2). The instrument employed was a calibrated Beckman Mercury Vapour Meter, Model K23, which measures only mercury vapour concentration.

TABLE 2

\begin{tabular}{l|cc}
\hline \multirow{2}{*}{ Time } & \multicolumn{2}{|c}{ Mercury in air $\left(\mathrm{mg} / \mathrm{m}^{3}\right)$} \\
\cline { 2 - 3 } & At floor level & At breathing height \\
\hline 11.45 a.m. & Air mover off-no ventilation \\
11.45 & $2 \cdot 1-2 \cdot 9$ & $1 \cdot 7$ \\
12.30 p.m. & $4 \cdot 0$ & $2 \cdot 9$ \\
12.37 & Air mover on-updraft ventilation \\
12.47 & $3 \cdot 3$ & $1 \cdot 7$ \\
1.07 & $1 \cdot 7$ & $1 \cdot 1$ \\
1.37 & $1 \cdot 1$ & $1 \cdot 1$ \\
2.07 & $1 \cdot 1$ & $1 \cdot 1$ \\
2.08 & Air flow reversed-downdraft ventilation \\
2.52 & $1 \cdot 5$ & $1 \cdot 5$ \\
\hline
\end{tabular}

In Victoria, Australia, the MAC for mercury in air is $0.1 \mathrm{mg} / \mathrm{m}^{3}$.

\section{Discussion}

There seems little doubt from the clinical description and subsequent investigation that at least three and probably all of the men reported in our small series suffered from acute bronchopulmonary irritation due to inhalation of mercury vapour. The results of the estimations of mercury-in-air in a later simulation support the diagnosis.

Two points are worthy of further discussion.

(a) Work in a confined space is well known to increase the dangers of inhalation of toxic materials. There are 'Entry into Confined Spaces Regulations 1954 ' in Victoria, Australia, which define a 'confined space' in terms of either lack of oxygen or the presence of harmful fumes. The Regulations detail certain procedures amongst which is included the blowing of sufficient fresh air into the space to remove the harmful fumes. The wearing of a suitable respiratory protective device may be permitted as an alternative procedure.

At first sight the air movement of about $85 \mathrm{~m}^{3} /$ minute, giving approximately seven air changes per hour, would appear to be sufficient to lower the concentration of toxic material in the tank atmosphere, by dilution, to a degree that would render it harmless. However, from Table 2 it can be seen that after ventilation, the concentration of mercury vapour at breathing height, although lowered, remained at toxic levels whether the ventilation was updraft or downdraft. This was unexpected, as previous experience of a factory floor heavily contaminated with 
mercury had shown that downdraft ventilation had substantially reduced the concentrations in the breathing zone (Milne, Christophers, and de Silva, 1970). The explanation probably lies in the air turbulence caused by high velocity air movement through a small entry portal, i.e., the air, eddying over the large surface area presented by the numerous minute mercury globules, produced mercury vapour at a rate sufficient to maintain an air equilibrium concentration of $1.1 \mathrm{mg} \mathrm{m}^{-3}$ with upward air flow, and $1.5 \mathrm{mg} \mathrm{m}^{-3}$ on downdraft. Moreover, the uniform mixing of the mercury vapour with the tank atmosphere, caused by the turbulent flow, meant that no advantage was gained by working in any particular situation within the tank. At the time the men were affected, the updraft air was drawn first over the mercury surface and subsequently through the operators' breathing zone.

In the simulation, reversal of the direction of the flow did not lower the equilibrium concentration but actually increased it to $1.5 \mathrm{mg} \mathrm{m}^{-3}$, which was almost certainly due to the mixing effect of the air turbulence. Thus the common concept of a gradient of mercury concentration decreasing from the floor upwards to the level of the operators' breathing zone was not valid.

A further factor to be considered is the temperature inside the tank. The small floor heating pipe probably had a slight but not marked effect in increasing the air temperature. The workmen noticed that conditions were warm while working, and, though no precise figures are available, it is justifiable to assume that any temperature increase would have been important because of the resultant increase in the mercury vapour pressure. At $18^{\circ} \mathrm{C}$, which is a comfortable room temperature, the equilibrium concentration of mercury-in-air is about $10 \mathrm{mg} \mathrm{m}^{-3}$; at $25^{\circ} \mathrm{C}$ it has doubled; and at $30^{\circ} \mathrm{C}$ trebled. At this last temperature, which corresponds to a rather warm summer's day in Melbourne, the saturated vapour pressure of mercury produces 300 times the maximum allowable concentration of mercury in air. The temperature at the time of the simulation inside the tank was $62^{\circ} \mathrm{F}$ (approx. $17^{\circ} \mathrm{C}$ ).

(b) The clinical picture in our group was similar to the characteristic respiratory irritation described by other authors. Three of the four noted cough, gasping respirations and a tight feeling in the chest, and the fourth complained of a dry throat and mild tightness in the chest. A typical feature was delay in the onset of symptoms from the time of exposure. No one noted any real discomfort whilst exposed, but about four hours later, at home, three men were markedly worse with acute severe respiratory distress.

This latent interval or lag period of several hours is a feature, also, of 'metal fume fever' suffered by brass founders and others inhaling the fumes of metals such as zinc and copper; and of the respiratory symptoms which follow inhalation of delayed irritant gases such as nitrogen dioxide (nitrous fumes).

Hallee (1969) has recently reported dyspnoea on exertion in a 31-year-old man five months after exposure to mercury vapour. Lung biopsy then revealed minimal interstitial pulmonary fibrosis. There was persistent mild dyspnoea on exertion one year after exposure. The four men in our series, three of whom were severely affected by mercury vapour, have made apparently complete recoveries clinically.

Mercury vapour is colourless and odourless and the similarity of the general clinical picture of mercury vapour inhalation to acute influenzal bronchitis could be misleading without a clear occupational history. The possibility of ultimate death must be borne in mind if there is evidence of severe exposure, and intensive respiratory care may be required in view of the severe pathological changes that have been noted at post mortem in similar cases.

It is also important to note that mercury provides a continuing source of contamination. We have shown that apparently adequate general ventilation may prove to be useless in these circumstances and, in our view, personal respiratory protection using an efficient air-supplied respirator is the required equipment to enter with safety a confined space containing mercury.

We are grateful to Dr. F. N. Dwyer who originally brought this problem to our attention. Mrs. M. Griffiths has patiently and efficiently typed many drafts. Dr. R. Farnbach, Chief Health Officer, has kindly given permission to publish.

\section{References}

Campbell, N. S. (1948). Acute mercurial poisoning by inhalation of metallic vapour in an infant. Canad. med. Ass. J., 58, 72-75.

Christensen, H., Krogh, M., and Nielsen, M. (1937). Acute mercury poisoning in a respiration chamber. Nature (Lond.), 139, 626.

Haddad, J. K., and Sternberg, E., Jr. (1963). Bronchitis due to acute mercury inhalation. Amer. Rev. resp. Dis., 88, 543-545.

Hallee, T. J. (1969). Diffuse lung disease caused by inhalation of mercury vapor. Amer. Rev. resp. Dis., 99, 430-436.

Hopmann, A. (1928). Acute poisoning from mercury vapour. Bull Hyg. (Lond.), 3, 585. (Translated by T. M. Legge.)

Hunter, D. (1957). The Diseases of Occupations, 2nd ed., p. 275. English Universities Press, London.

King, G. W. (1954). Acute pneumonitis due to accidental exposure to mercury vapor. Ariz. Med., 11, 335.

Matthes, F. T., Kirschner, R., Yow, M. D., and Brennan, J. C. (1958). Acute poisoning associated with inhalation of mercury vapor. Pediatrics, 22, 675-688.

Milne, J., Christophers, A., and de Silva, P. (1970). Mercurial intoxication, clinical and occupational features. (In preparation.)

Tennant, R., Johnston, H. J., and Wells, J. B. (1961). Acute bilatera pneumonitis associated with the inhalation of mercury vapor. Conn. Med., 25, 106-109.

Received for publication March 5, 1970 